\title{
APLIKASI ILUSTRASI KARAKTER PUNAKAWAN PADA KEMASAN TEH CELUP
}

\author{
Yulius Widi Nugroho ${ }^{1}$ \\ Sekolah Tinggi Teknik Surabaya, Surabaya ${ }^{l}$ \\ yulius@stts.edu
}

\begin{abstract}
Abstrak
Kemasan teh celup selama ini berfungsi sebagai pelindung produk dan alat komunikasi ke calon konsumen, dan pada perancangan ini kemasan teh celup diusahakan bisa memberi makna yang jauh lebih luas dari sekadar pelindung. Dengan mengusung karakter punakawan, kemasan teh celup dibuat sedemikian rupa sehingga tidak hanya memenuhi fungsi estetika, namun juga fungsi entertain sekaligus mengenalkan budaya lokal. Karakter punakawan dipilih karena merupakan simbol rakyat jelata yang sudah melegenda di kalangan masyarakat Indonesia khususnya di Jawa. Tujuan pengkaryaan adalah menjadikan karaker Punakawan untuk menjadi elemen desain kemasan teh. Metode perancangan desain dilakukan dari mencari data referensi tentang karakter Punakawan dan perancangan kemasan makanan khususnya kemasan teh. Desain kemasan teh celup ini diharapkan dapat memperkaya khasanah dunia desain khususnya pada desain kemasan, kemudian dapat direalisasikan secara nyata pada produk teh kemasan di Indonesia.
\end{abstract}

Kata kunci: Kemasan, Ilustrasi, Punakawan, Teh Celup

\section{Abstract}

The tea bag packaging has been functioning as a protective product and communication tool to prospective consumers, and in this design the tea bag packaging can provide a much broader meaning than just protective. By carrying the character of the punakawan, the tea bag packaging is made in such a way that it not only fulfills the aesthetic function, but also the function of entertainment while introducing local culture. The character of the punakawan was chosen because it is a symbol of the people who have been legendary in Indonesian society, especially in Java. The aim of the work is to make Punakawan workmanship a design element of tea packaging. The design method is done by finding reference data about Punakawan's character and designing food packaging, especially tea packaging. The design of the tea bag packaging is expected to enrich the realm of the design world, 
especially in the design of the packaging, then it can be realized significantly in the packaging of tea products in Indonesia.

Key words: Packaging, Illustration, Punakawan, Tea Bag.

\section{PENDAHULUAN}

Pertumbuhan pasar industri makanan di Indonesia diharapkan terus mengalami peningkatan, Menurut Menteri Perindustrian Airlangga Hartarto mengatakan kementeriannya mencatat, pada triwulan II 2018, pertumbuhan industri makanan dan minuman mencapai 8,67 persen atau melampaui pertumbuhan ekonomi nasional sebesar 5,27 persen. Salah satu yang memberikan kontribusi terhadap pertumbuhan pasar dalam industri makanan dan minuman adalah bisnis minuman dalam kemasan. Pasar minum teh alam kemasan saat ini mengalami pertumbuhan yang cukup pesat. Tingginya minat masyarakat mengkonsumsi teh dalam kemasan mempunyai prospek yang sangat cerah, mendorong banyak perusahaan untuk ikut terjun kedalam industri minuman teh siap minum dalam kemasan (TSMDK).

Teh adalah minuman sehari-hari orang Indonesia dari segala kalangan, dan teh celup adalah produk teh yang paling populer dibeli orang jika ingin minum teh dan membuatnya sendiri atau juga disajikan di restoran. Kepopuleran pasar teh di Indonesia sampai perusahaan tingkat dunia pun menjual teh di Indonesia dengan mengakusisi merek lokal. Banyak yang mencoba peruntungan di bisnis teh celup dengan menghadirkan teh celup dengan berbagaimacam konsep seperti teh dengan rasa buah, atau dengan kemasan yang unik.

Klimchuk \& Krasovev (2007:33) menjelaskan bahwa: desain kemasan adalah bisnis kreatif yang mengaitkan bentuk, struktur, material, warna, citra, tipografi, dan elemen-elemen desain dengan informasi produk agar produk dapat dipasarkan. Desain kemasan berlaku untuk membungkus, melindungi, mengirim, mengeluarkan, menyimpan, mengidentifikasi, dan membedakan sebuah produk dipasar. Desain kemasan yang efektif adalah yang fokus pada konsumen yang menjadi target audience. Bentuk kemasan juga membangkitkan berbagai emosi tertentu dan memiliki konotasi spesifik. Material yang digunakan untuk kemasan juga mempengaruhi konsumen yang akhirnya berpengaruh pada penjualan. 
Salah satu aspek yang paling berpengaruh dalam pemasaran adalah faktor budaya. Pemasar dan produsen harus mengetahui pengaruh budaya dan seharusnya menyiapkan diri untuk menghadapi tantangan yang akan dihadapi akibat adanya aspek budaya ini. Hal ini karena setiap daerah dan batas wilayah memiliki budaya yang berbeda-beda. Sehingga Dalam membuat produk, budaya merupakan salah satu faktor yang akan mempengaruhi karakteristik produk tersebut.

Dalam rangka penggunaan aspek budaya pada pemasaran akan digunakan untuk membuat konsep kemasan teh celup. Penulis memilih karakter klasik Punakawan untuk diaplikasikan pada kemasan teh celup tersebut. Punakawan adalah karakter yang khas dalam wayang Indonesia. Mereka melambangkan orang kebanyakan. Karakternya mengindikasikan bermacam-macam peran, seperti penasihat para ksatria, penghibur, kritisi sosial, badut bahkan sumber kebenaran dan kebijakan. Dalam Wayang Jawa karakter punakawan terdiri atas Semar, Gareng, Bagong, dan Petruk.

Dari latar belakang di atas dapat dirumuskan permasalahannya, yaitu: Bagaimana karakter Punakawan dapat digunakan sebagai aplikasi desain pada kemasan teh celup sehingga kemasan menjadi menarik? Kemudian tujuan pengkaryaan ini adalah membuat karakter punakawan yang sudah populer dapat digunakan sebagai elemen desain kemasan teh celup. Kemasan tersebut diusahakan semenarik mungkin, dan dengan konsep tersebut diharapkan dapat membuka khasanah dunia desain khususnya pada desain kemasan, kemudian dapat direalisasikan secara nyata pada produk teh kemasan di Indonesia.

\section{KAJIAN TEORI}

\section{Sejarah Teh}

Teh adalah minuman yang mengandung kafein, yang dibuat dengan cara menyeduh daun, pucuk daun, atau tangkai daun yang dikeringkan dari tanaman Camellia Sinensis dengan air panas. Teh yang berasal dari tanaman teh dibagi menjadi 4 kelompok: teh hitam, teh oolong, teh hijau, dan teh putih. Istilah "teh" juga digunakan untuk minuman yang dibuat dari buah, rempah-rempah atau tanaman obat lain yang diseduh, misalnya, teh rosehip, camomile, krisan dan Jiaogulan. Teh yang tidak mengandung daun teh disebut teh herbal. 
Menurut Jane Pettigrew (2002), Teh (Camellia sinensis) berasal dari Negeri Tiongkok, tepatnya di provisnsi Yunnan, bagian barat daya Cina. Teh Cina pada awalnya memang digunakan untuk bahan obat - obatan (Abad ke-8 SM), itupun sudah berumur ribuan tahun riwayatnya. Orang - orang Cina pada waktu itu mengunyah teh (770 SM - $476 \mathrm{SM}$ ) mereka menikmati rasa yang menyenangkan dari sari daun teh. Pada zaman pemerintahan dinasti Han (221 SM - $8 \mathrm{M})$, teh mulai diolah dengan pemrosesan yang terbilang sederhana, dibentuk membulat, dikeringkan dan disimpan, teh mulai dijadikan sebagai minuman, teh diseduh dan dikombinasikan dengan ramuan lain (misalnya jahe) dan kebiasaan ini melekat kuat dengan kebudayaan masyarakat Cina.

Ternyata Pengaruh Teh Cina menulari Jepang, konsumsi teh menyebar melalui kebudayaan Cina yang akhirnya menjangkau setiap aspek masyarakat. Bibit teh dibawa ke Jepang oleh seorang pendeta Budha bernama Yeisei yang melihat bahwa teh Cina mampu meningkatkan konsentrasi saat bermeditasi. Ia dikenal sebagai Bapak Teh di Jepang, karena asal muasal inilah, teh Jepang erat kaitannya dengan Zen Buddhism. Teh diminati pula dalam kekaisaran Jepang, yang kemudian menyebar dengan cepat di kalangan istana dam masyarakat Jepang.

Teh bahkan menjadi budaya dan bagian dari seni yang dituangkan dalam Japanese Tea Ceremony (Cha-no-yu atau air panas untuk teh). Upacara ini membutuhkan latihan yang panjang, bahkan hingga bertahun - tahun. Performasi dari Cha-no-yu adalah menjunjung tinggi kesempurnaan, kesopanan, pesona dan keanggunan.

Kemudian budaya mengkonsumsi teh yang sudah dilakukan di Cina dan Jepang terdengar hingga Eropa. Portugis menjalin hubungan dagang dengan Cina, mengembangkan jalur dagang dengan mengkapalkan teh ke Lisbon dan kemudian kapal - kapal Belanda berangkat ke Perancis, Negeri Belanda dan Baltik, teh kemudian semakin populer ke belahan dunia barat. Teh singgah di Eropa pada zaman Elizabeth I, dan kemudian juga menjadi tren dalam kerajaan Belanda. Teh menjadi minuman yang mahal pada waktu itu, sehingga para pedagang teh mendapatkan kemakmuran darinya.

Masyarakat Belanda sangat menggemari teh, dan konsumsi teh pun meningkat pesat, meskipun demikian banyak yang mempertanyakan manfaat teh, 
dan berbagai dampak negatif lainnya. Apapun itu, masyarakat pada umunya tidak lagi mempermasalahkan atau terpengaruh dan kembali menikmati minuman teh ini. Teh menjadi bagian dari masyarakat di Eropa, dan ragam kombinasi konsumsi teh pun dicoba, seperti mencampurkan teh dengan susu. Pada masa itupun layanan teh disajikan pertama kali di restoran. Kedai minuman pun memberikan perkakas teh portabel lengkap disertai alat pemanasnya. Pada tahun 1650, orang - orang Belanda sangat aktif dalam perdagangan sampai pada dunia Barat. Peter Stuyvesant yang membawa teh Cina ke Amerika pertama kali untuk koloninya (tempat itu kenal sebagai: New York sampai sekarang).

\section{Kemasan Teh Celup}

Teh dikenal dengan berbagai macam cara pembuatan, penyajian, dan pengemasannya. Berikut macam-macam kemasan teh yang beredar dan populer di masyarakat. (Ara Rossi: 2010)

a. Teh celup, dikemas dalam kantong kecil yang biasanya dibuat dari kertas dengan tali. Teh celup sangat populer karena praktis untuk membuat teh, tetapi pencinta teh kelas berat biasanya tidak menyukai rasa teh celup.

b. Teh saring, dikemas dalam kantong kecil yang biasanya dibuat dari kertas tanpa tali. Teh saring sangat populer karena praktis untuk membuat teh dalam kuantitas banyak dan menghasilkan lebih pekat dibandingkan teh celup.

c. Teh seduh (daun teh), dikemas dalam kaleng atau dibungkus dengan pembungkus dari plastik atau kertas. Takaran teh dapat diatur sesuai dengan selera dan sering dianggap tidak praktis. Saringan teh dipakai agar teh yang mengambang tidak ikut terminum. Selain itu, teh juga bisa dimasukkan dalam kantong teh sebelum diseduh. Mangkuk teh bertutup asal Tiongkok yang disebut gaiwan dapat digunakan untuk menyaring daun teh sewaktu menuang teh ke mangkuk teh yang lain.

d. Teh yang dipres, yaitu teh dipres agar padat untuk keperluan penyimpanan dan pematangan. Teh pu erh dijual dalam bentuk padat dan diambil sedikit demi sedikit sewaktu mau diminum. Teh yang sudah dipres mempunyai masa simpan yang lebih lama dibandingkan daun teh biasa. 
e. Teh stik, dikemas di dalam stik dari lembaran aluminium tipis yang mempunyai lubang-lubang kecil yang berfungsi sebagai saringan teh.

f. Teh instan, berbentuk bubuk yang tinggal dilarutkan dalam air panas atau air dingin. Pertama kali diciptakan pada tahun 1930-an tetapi tidak diproduksi hingga akhir tahun 1950-an. Teh instan ada yang mempunyai rasa vanila, madu, buah-buahan, atau dicampur susu bubuk.

Teh Celup akan difokuskan untuk dibahas karena memang dari tujuan perancangan adalah membuat kemasan teh celup. Karakteristik teh celup adalah teh di bungkus atau di kemas pada bahan kertas yang berpori, sehingga dicelupkan ke air hanya sari tehnya saja yang larut ke air, sedangkan teh (ampas teh) masih berada pada kemasan kertas tadi. Kemudian gantungan teh celup biasanya ikut disajikan bersama dengan cangkir atau gelasnya, sehingga penikmat teh bisa menyedu teh sendiri menurut selera kekentalannya.

\section{Karakter Punakawan}

Sebelum mengenal lebih jauh tentang Punakawan, baiknya mengenal terlebih dahulu tentang Wayang. Wayang adalah salah satu seni pertunjukan tradisional yang paling luas penyebarannya di Indonesia hingga sekarang, tersebar di pulau-pulau yang paling padat penduduknya seperti Jawa, Madura, Bali, dan beberapa daerah lain di Sumatera. Dalam batasannya, wayang merupakan agama kedua bagi masyarakat Jawa (pada khususnya) karena memberikan nilai-nilai kehidupan seperti ajaran, tuntunan dan tatanan nilai kultural baik melalui presentasi jalan cerita maupun citra para tokoh.

Asal-usul wayang telah menjadi perdebatan beberapa ahli sejarah. Dr. G. A.J Hazeu yang menulis tentang wayang jawa dalam disertasinya yang berjudul Bijdrage tot de Kennis van het Javaansche Tooneel. Dr. Hazeu berpendapat bahwa wayang adalah tradisi asli Jawa dikarenakan banyaknya istilah dalam pewayangan yang menggunakan kosa kata bahasa Jawa misalnya kepyak, blencong dan lainlain. Selain itu, ditemukan suatu susunan unik pada rumah tradisional Jawa yaitu dengan membuat suatu ruangan khusus pertunjukkan ringgit (wayang). Menurut Dr. Hazeu pengertian wayang adalah walulang inukir (kulit yang diukir) dan dilihat bayangannya pada kelir. Dengan demikian, wayang yang dimaksud adalah wayang 
kulit yang seperti kita kenal sekarang. Sejak tahun 1950, buku-buku pewayangan seolah sepakat bahwa wayang memang berasal dari pulau Jawa dan sama sekali tidak diimpor dari negara lain. (G. A.J Hazeu: 1897)

Pendapat lain berasal dari Dr. W. Rassers yang menyatakan bahwa pertunnjukkan wayang Jawa berasal dari India. Karena di India memang ada suatu pertunjukkan yang menggunakan efek bayangan seperti wayang Jawa. Peneliti lain yang sependapat dengan DR. Rassers adalah Dr. N. J. Krom yang sama-sama berpendapat bahwa wayang Jawa berasal dari India. Ia memperkirakan bahwa wayang merupakan hasil karya cipta tradisi Hindu dan Jawa. Ada pula ahli lain yang menyatakan bahwa wayang berasal dari Cina, karena pada masa Kaisar Wu Ti terdapat pertunjukkan bayangan serupa dengan wayang. Dari Cina, pertunjukkan bayangan tersebut sampai ke India lalu kemudian menyebar ke Indonesia.

Budaya wayang diperkirakan sudah ada sejak pemerintahan Prabu Airlangga, raja Kahuripan (976-1012). Karya sastra yang menjadi bahan cerita wayang ditulis oleh pujangga Indonesia sejak abad X. Antara lain, Kitab Ramayana Kakawin berbahasa Jawa Kuno yang merupakan gubahan dari Kitab Ramayana karangan Walmiki, India. Kemudian Karya Empu Kanwa, Arjunawiwaha Kakawin yang merupakan gubahan dari Kitab Mahabharata yang didalamnya diceritakan kembali dengan memasukkan falsafah Jawa.

Punakawan merupakan tokoh-tokoh dalam pewayangan yang berbentuk aneh dan lucu, termasuk watak dan tingkah polahnya. Tokoh wayang ini tidak ada dalam cerita wayang versi mitologi Hindu seperti Ramayana atau Mahabharata. Secara umum, punakawan terdiri dari empat tokoh. Yaitu Semar, Petruk, Nala Gareng, dan Bagong. Sekarang mari kita mengenal lebih dekat dengan keempat tokoh Punakawan.

Salah seorang Wali Songo yang telah mengadaptasi wayang Beber menjadi wayang kulit adalah Sunan Kalijaga. Beliau menciptakan karakter-karakter dalam wayang kulit dengan tujuan agar masyarakat senantiasa mengingat Allah Swt. (Gusti Allah). Dari banyaknya karakter wayang kulit, erdapat beberapa karakter wayang yang sangat unik, yaitu tokoh Punakawan. Penambahan tokoh Punakawan ini bisa dibilang telah keluar dari pakem asli wayang yang identik dengan epik Hindu-Budha. Tokoh Punakawan ini menyimbolkan karakter manusia pada 
umumnya. Jika dalam wayang Jawa tokoh Punakawan terdiri dari Semar, Gareng, petruk dan Bagong. Maka dalam wayang Bali, tokoh Punakawan terdiri dari dua abdi Pandawa bernama Malen dan Merdah serta dua abdi dari Kurawa yaitu Delem dan Sangut.

Secara etimologis, kata Punakawan berasal dari dua suku kata yaitu Puna yang berarti susah dan kawan yang berarti teman atau Kanca. Jika arti kata ini digabungkan, maka berarti teman di kala susah. Ada pula pendapat yang menyebutkan bahwa Puna berarti terang, sehingga artinya menjadi teman yang mengajak kepada jalan yang terang atau lurus. Bahkan, jika nama-nama para tokoh Punakawan digabungkan akan menjadi Bergegaslah meraih kebajikan serta tinggalkan sesuatu hal yang buruk. Tokoh-tokoh Punakawan dalam pewayangan Jawa adalah:

a. Semar

Semar bernama lengkap Kyai Lurah Semar Badranaya. Ada yang berpendapat bahwa nama Semar berasal dari kata dalam bahasa Arab Simaar yang berarti paku. Menyimbolkan kokohnya ajaran agama Islam laksanan paku yang kokoh menancap. Ada pula pendapat lain menyebutkan bahwa nama Semar berasal dari kata Samara (bergegas). Semar merupakan seorang tokoh berkarakter bijaksana, rendah hati, jujur dan penuh kedalaman ilmu. Semar merupakan tokoh yang sangat dihormati dan menjadi penasihat bagi para ksatria dan rekan-rekannya. Dalam filosofi wayang, jari telunjuk Semar yang seakan menuding menyimbolkan rasa keinginan yang demikian kuat untuk dapat menciptakan sesuatu. Sedangkan pandangan matanya yang menyipit mengandung makna rasa keseriusan, ketekunan dan ketelitian dalam mencipta.

Menurut seorang ahli sejarawan yaitu Dr. Slamet Muljana, tokoh Semar ini ditemukan pertama kalinya dalam kitab sastra zaman Majapahit Sudamala. Di dalam karya sastra kuno tersebut, tokoh Semar bernama Sudamala. Tokoh ini bahkan dapat ditemukan reliefnya pada Candi Sukuh. Sudamala digambarkan sebagai seorang abdi dari Sahadewa dari keluarga Pandawa. Pada perkembangan selanjutnya, tokoh Semar tetap dipertahankan bahkan mengalami kenaikan status. Semar tidak lagi diceritakan sebagai seorang abdi atau hamba atau rakyat jelata, 
namun merupakan titisan dari Batara Ismaya. Batara Ismaya adalah kakak dari Raja para Dewa, Batara Guru.

b. Gareng

Gareng bernama lengkap Nala Gareng yang berasal dari kata Nala Khairan (memperoleh kebaikan). Gareng merupakan anak pertama Semar. Ia digambarkan denga fisik yang memiliki kekurangan yaitu cacat pada kaki, tangan dan mata. Kekurangan fisik Gareng memiliki makna tersendiri yaitu cacat pada kaki berarti dalam hidupnya seorang manusia harus senantiasa berhati-hati. Cacat pada tangan berarti manusia bisa saja berikhtiar melalui berbagai macam cara, namun Allah Swt. lah yang akan menentukan. Cacat pada mata melambangkan bahwasanya manusia harus dapat memahami realitas kehidupan yang sesungguhnya.

c. Petruk

Nama Petruk berasal dari kata Fat ruk yang bermakna tinggalkanlah. Ia adalah putra kedua Semar yang memiliki gambaran fisik yang unik yaitu hidung panjang. Hidung panjang ini bukan berarti Petruk suka berbohong seperti kisah Pinokio. Hidung panjang ini melambangkan bahwasanya akal pikiran itu harus panjang atau luas. Jika hendak melakukan sesuatu harus melalui proses pemikiran yang panjang agar tidak menyesal di kemudian hari. Petruk memiliki sifat humoris, cerdas dan pandai bertutur kata.

Dalam dunia pewayangan, disebutkan bahwa Petruk merupakan anak seorang pendeta raksasa yang bermukim di suatu tempat di dalam laut yang bernama Begawan Salantara. Nama aslinya adalah Bambang Pecruk Panyukilan dan merupakan seseorang yang sakti mandraguna. Ia berkelana untuk menguji kesaktiannya. Ia lantas bertemu dengan Bambang Sukodadi, lalu keduanya terlibat pertempuran sengit yang menyebabkan cacatnya tubuh tampan mereka. Perkelahian ini akhirnya berhasil dihentikan oleh Semar. Setelah mendapatkan petuah, Petruk dan Bambang Sukodadi menyerahkan hidup mereka untuk berguru kepada Semar. Karena mereka telah mengalami perubahan fisik masing-masing, Bambang Pecruk Panyukilan berganti nama menjadi Petruk. Sedangkan Bambang Sukodadi mengubah namanya menjadi Gareng. 


\section{d. Bagong}

Bagong merupakan anak bungsu Semar. Namanya berasal dari kata al $\mathrm{Ba}$ gho ya yang bermakna perkara buruk. Ia memiliki gambaran fisik persis seperti ayahandanya, Semar. Bertubuh agak gemuk, humoris terutama saat berhadapan dengan persoalan serius dan sering berlagak bodoh. Ia mencerminkan sifat manusia yang harus sederhana dalam hidup, memiliki kesabaran dan tidak mengagungagungkan kehidupan di dunia. Bagong mewakili gambaran manusia yang sesungguhnya bahwa manusia sejati adalah manusia yang memiliki kelebihan dan kekurangan. (Ardian Kresna: 2012)

Tokoh-tokoh dalam wayang biasanya merupakan ksatria, pendeta atau pun dewa. Sedangkan tokoh-tokoh Punakawan mewakili suara rakyat jelata. Filosofi yang terkandung dalam para tokoh Punakawan ini sangat erat kaitannya dengan kebijaksanaan yang terkandung dalam agama Islam, bahwa adalah manusiawi jika manusia memiliki kekurangan. Bahwa dalam kehidupan ini, sudah selayaknya kita melihat dengan pikiran dan mata terbuka, agar dapat memaknai kehidupan duniawi yang akan menghantarkan kita kepada kehidupan akhirat kelak.

\section{METODE PENELITIAN}

Metodologi ilmiah untuk proses penciptaan umumnya terdapat tiga tahapan yaitu: tahap eksplorasi, tahap perancangan, dan tahap perwujudan. (Gustami: 2000). Pertama, tahap eksplorasi yaitu aktivitas menggali sumber ide, menjelajahi dan mengumpulkan data \& referensi, pengolahan dan analisa data. Hasil dari penjelahan atau analisis data tersebut dijadikan dasar untuk membuat rancangan atau desain.

Kedua, tahap perancangan dengan memvisualisasikan hasil dari penjelajahan atau analisa data kedalam alternatif desain dengan sketsa, untuk kemudian ditentukan sketsa terpilih dan dijadikan acuan dalam pembuatan rancangan final yang berupa proyeksi, potongan, detail, dan perspektif.

Ketiga, tahap perwujudan rancangan terpilih menjadi prototipe sambil menyempurnakan karya sesuai dengan ide awal. Prototipe ini bisa dalam bentuk 
miniatur atau ukuran yang sebenarnya. Jika hasil tersebut dianggap telah dianggap sempurna maka dilanjutkan dengan pembuatan karya yang sesungguhnya dengan diproduksi nyata.

Ketiga proses tersebut bisa dijabarkan sekaligus dari awal hingga akhir melalui beberapa tahapan, yaitu:

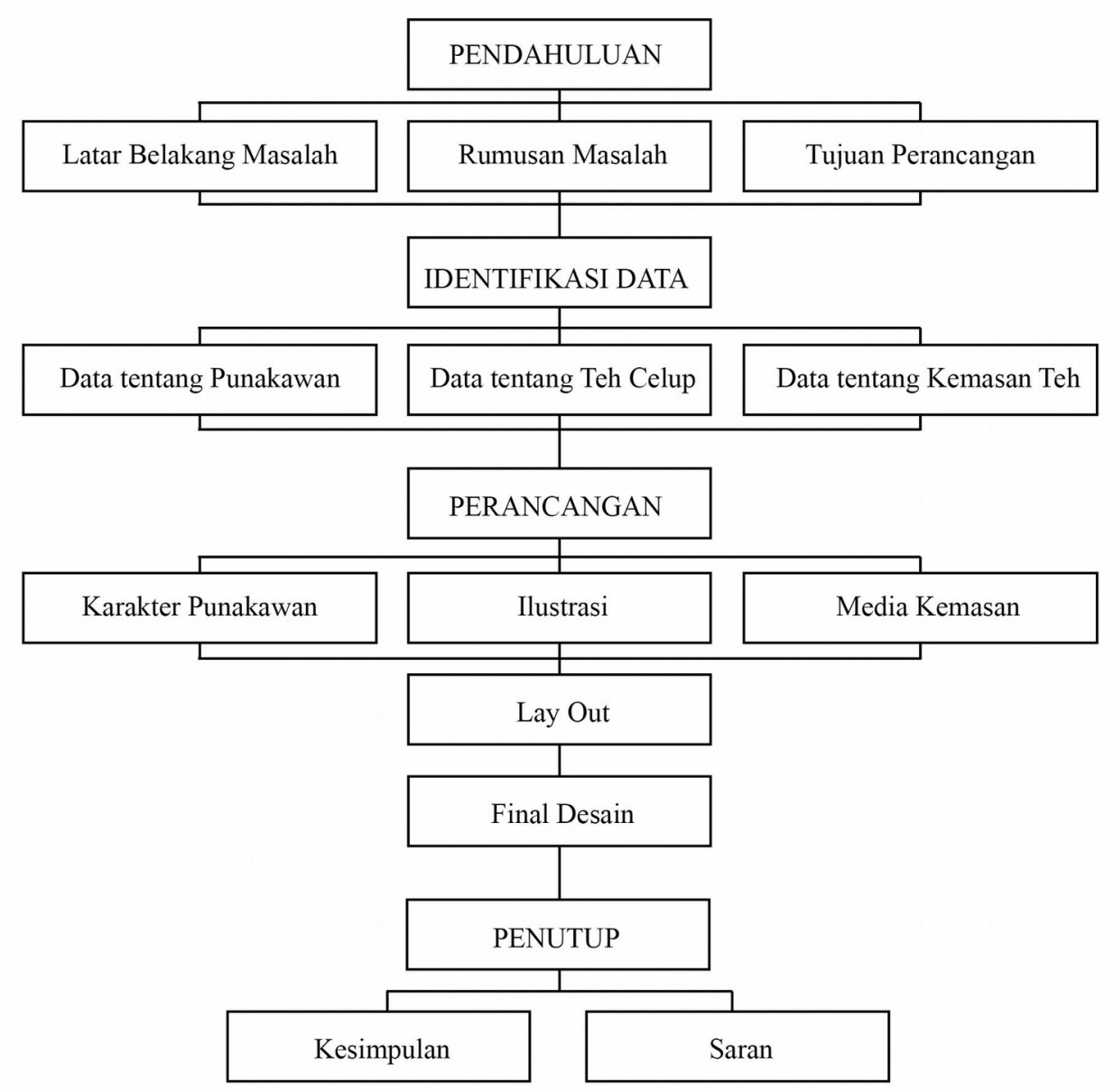

Bagan 1. Metode Perancangan dan proses desain kemasan teh Punakawan

\section{HASIL DAN PEMBAHASAN}

Dalam proses penciptaannya Karakter Punakawan lebih bebas dalam menuangkan ide dan tidak seketat dengan penciptaan wayang klasik yang banyak pakem atau aturan yang mengikat baik dari sisi bentuk fisik, konsep filosofi, sejarah, dan budaya yang ada. Dimulai dengan ilustrasi karakter punakawan 
berdasarkan berbagai sumber. Ditangkap bahwa punakawan adalah refleksi rakyat jelata dan di cerita pewayangan sering dijadikan media humor dan hiburan.
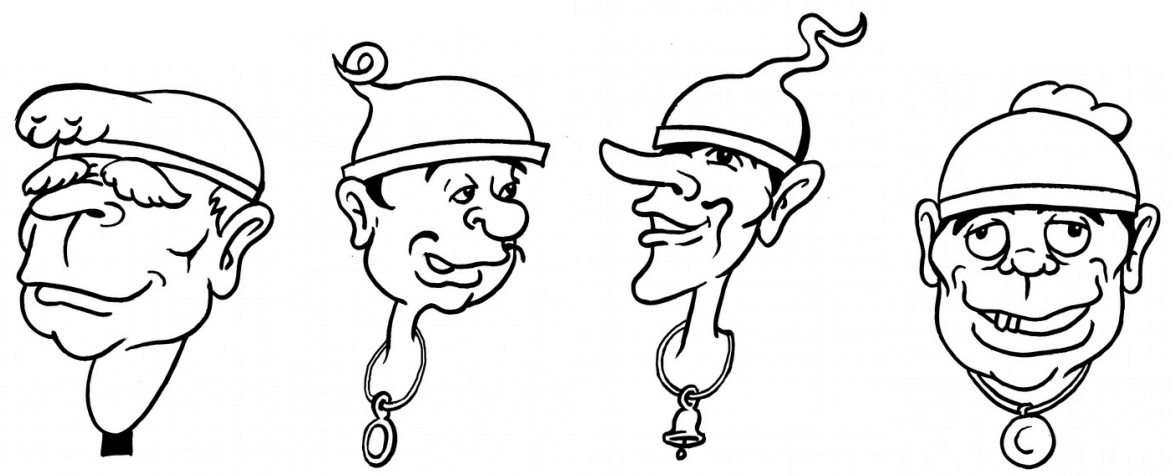

Gambar 1. Karakter wajah punakawan, dari kiri ke kanan;

\section{Semar, Gareng, Petruk, Bagong}

Sumber: Dokumentasi Penulis

Karakter-karakter tersebut menggunakan teknik ilustrasi kartun dengan menampilkan garis outline yang kuat dengan tanpa pewarnaan atau hitam putih. Kemudian dari karakter-karakter tersebut dikembangkan untuk variasi dengan pose berbeda. Karakter dibuat lucu atau konyol menyesuaikan karakter dasar punakawan sebagai penghibur.

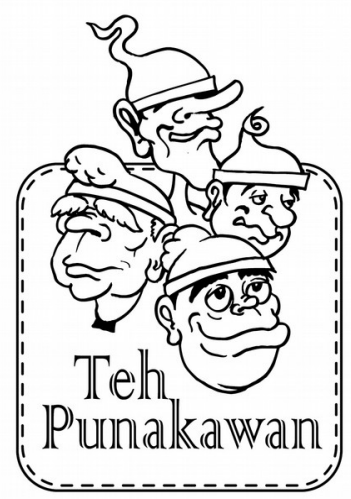

Gambar 2. Karakter wajah punakawan setelah di lay-out

Sumber: Dokumentasi Penulis 
Setelah karakter-karakter tersebut sudah dibuat seperti Gambar 1.2, layout tersebut bisa digunakan sebagai logo yang nantinya ditampilkan pada desain kemasan teh celup maupun media-media pendukung lainnya.

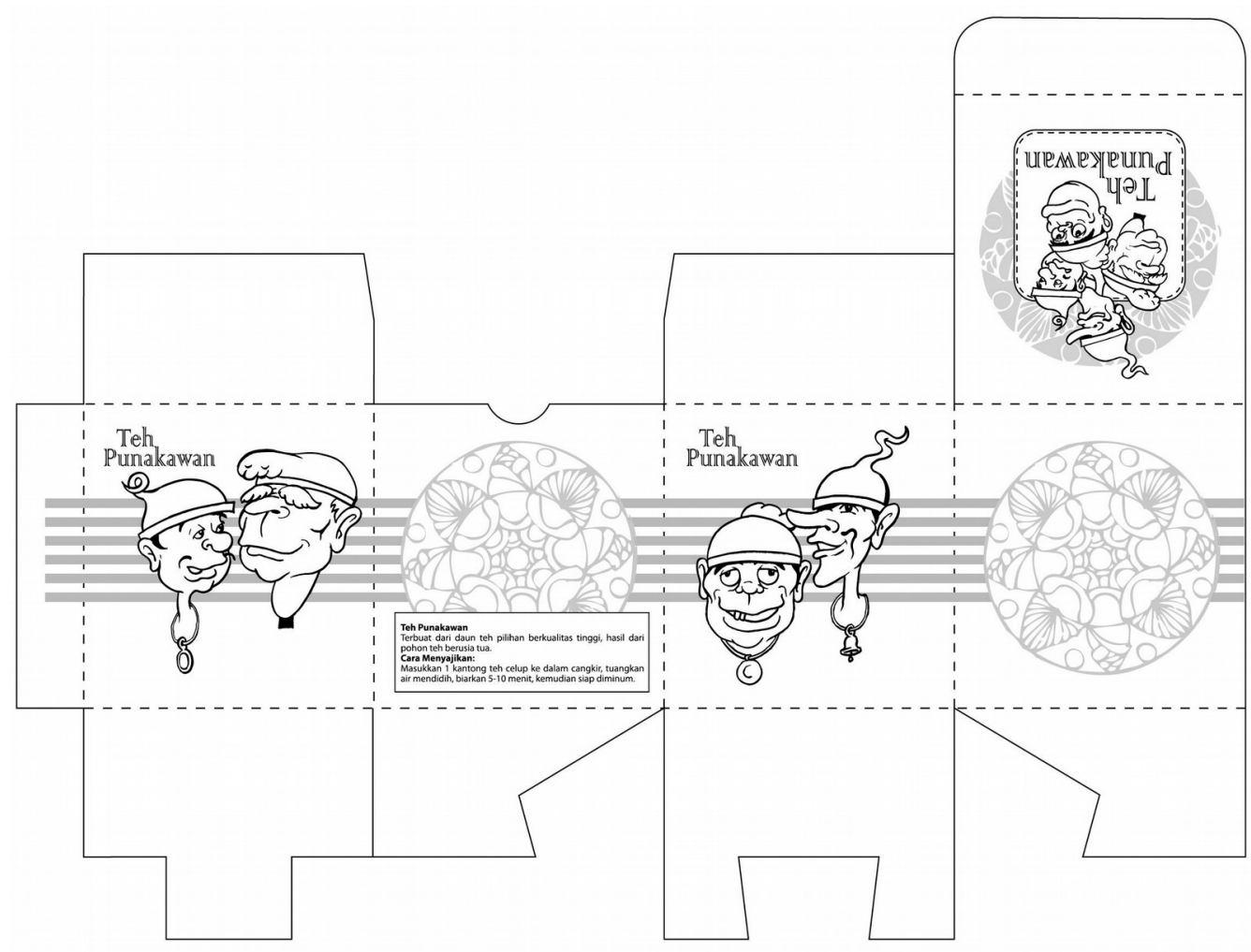

Gambar 3. Layout kemasan luar teh celup

Sumber: Dokumentasi Penulis

Kemudian material desain di lay-out untuk kemasan luar dengan konsep yang tidak jauh berbeda yaitu hitam-putih sederhana dengan mengaplikasikan ornamen sederhana. Agar tampilan desain terkesan tidak terlalu sederhana dan masih bisa menampilkan kesan elegan dipilih bahan cetak yang spesial yaitu pemilihan kertas fancy dengan tekstur yang khas. Mengingat ini adalah produk makanan, harus ditampilkan juga komposisi nutrisi dan cara penyajian. 


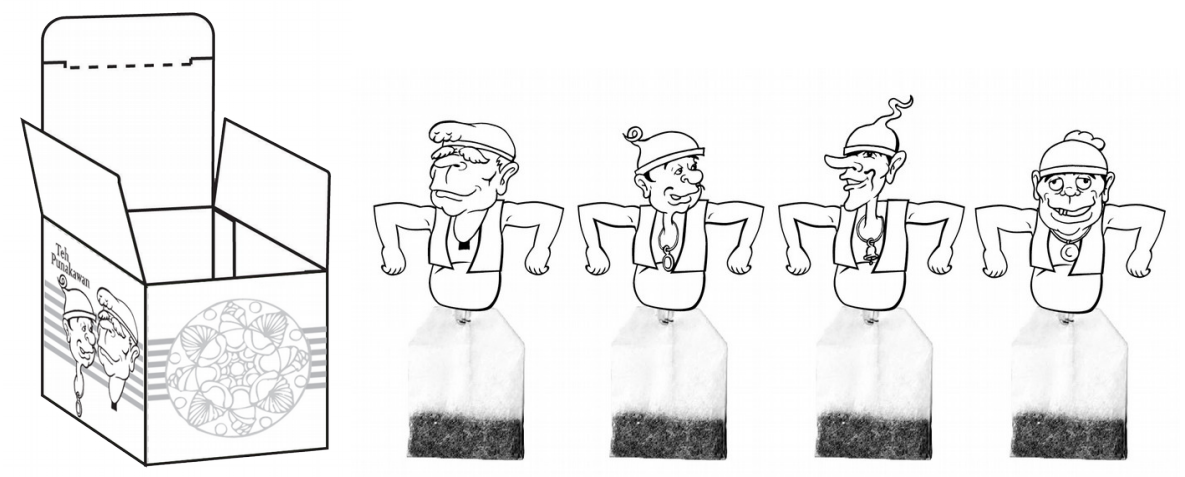

Gambar 4. Kemasan Luar setelah dilipat dan Karakter diaplikasikan pada gantungan teh celupnya

Sumber: Dokumentasi Penulis

Untuk kemasan dalam karakter Punakawan dibuat setengah badan dengan pose tangan ke samping bertujuan dapat dikaitkan dengan bibir gelas atau cangkir. Dengan demikian seolah-olah nantinya karakter Punakawan sedang berendam ke dalam teh.
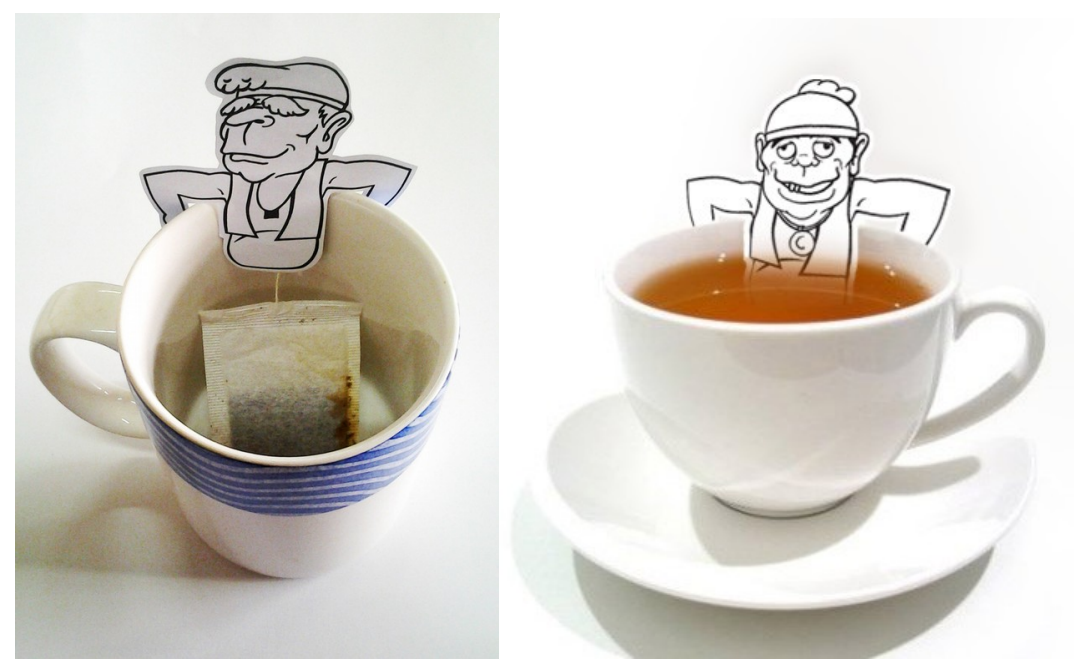

Gambar 5. Karakter diaplikasikan pada gantungan teh celupnya Sumber: Dokumentasi Penulis

Kemasan dalam didesain dengan ukuran $6 \times 6 \mathrm{~cm}$ dengan dicetak menggunakan kertas art paper 210gr kemudian dilaminasi. Tujuan laminasi ini 
adalah agar aman ketika kertas masuk ke dalam teh, tinta cetak tidak terlindungi sehingga tidak bereaksi dengan air teh.

\section{SIMPULAN DAN SARAN}

\section{Simpulan}

Karakter Punakawan merupakan figur yang menarik dan tak lekang oleh jaman. Mereka bisa hadir pada setiap masa dengan nuansa berbeda sesuai tren pada masanya. Punakawan yang diaplikasikan pada kemasan teh dapat menjadi elemen desain yang menarik sesuai tujuan pengkaryaan desain ini. Kemudian karakter Punakawan menjadikan penyeimbang antara sifat konservatif yang serba terbatas dan sifat progresive yang tidak mengenal batas, dengan memberi suasana yang lucu dan segar. Punakawan sebagai karya budaya asli bangsa sudah selayaknya untuk mendapatkan porsi yang lebih untuk penyeimbang dari karakter asing agar bisa menjadikan manusia Indonesia sebagai manusia yang sadar diri, sadar akan nilainilai kebaikan, keindahan dan bisa memahami budayanya sendiri.

\section{Saran}

Dengan penggunaan karakter punakawan pada kemasan teh ini diharapkan memperluas khasanah desain kemasan ataupun memperluas pengetahuan tentang budaya wayang khususnya punakawan. Seiring dengan pesatnya perkembangan teknologi, maka akan semakin mudah penyampaian maksud dan tujuan dalam membuat desain yang memiliki fungsi yang berbeda, tidak hanya menjalankan fungsi kemasan produk saja, tapi juga memainkan peran yang kompleks dalam masyarakat. Dalam hal ini, kemasan menjadi satu bentuk komunikasi sosial mengkomunikasikan informasi tentang produk. Sedangkan sebagai sebuah komunikasi visual, kemasan juga dapat memperluas informasi di mana kemasan tidak lagi hanya melibatkan informasi produk fungsional saja tapi juga informasi simbolik sosial.

\section{DAFTAR PUSTAKA}

Marianne R. Klimchuk, Sandra A. Krasovec, 2013. Packaging Design: Successful Product Branding From Concept to Shelf, 2nd Edition. John Wiley \& Sons Jane Pettigrew 2002. A Social History of Tea. National Trust 
Ara Rossi, 2010. 1001 Teh. Andi Offset, Yogyakarta

Godard Arend Johannes Hazeu, 1897, Bijdrage tot de kennis van het Javaansche tooneel, Boekhandel en Drukkerij voorheen E.J. Brill

Ardian Kresna, 2012. Punakawan - Simbol Kerendahan Hati Orang Jawa, Penerbit Narasi

Danu Widhyatmoko, 2014. Konsep Visual Perancangan Label Kemasan Madumadu Nusantara dengan Contoh Kasus Madu Sumbawa. Jurnal Wastucitra

Mahendra Sucipto 2016. Kitab Lengkap Tokoh-Tokoh Wayang dan Silsilahnya, Penerbit Narasi

Gustami, 2000. Konsep-Konsep di Balik Kriya Tradisional Indonesia Analisis

Desain Melalui Pendekatan Sosial-budaya. Yogyakarta: ITB.

Kompas.com 2014. Teh Kemasan dan Teh Seduh, Mana Lebih Sehat?, Penulis : Christina Andhika Setyanti Diakses pada tanggal 5 Desember 2018 dari https://ifestyle.kompas.com/read/2014/02/11/1638115/Teh.Kemasan.dan.Te h.Seduh.Mana.Lebih.Sehat.

Tempo.Co 2018. Industri Makanan dan Minuman Tumbuh 8,67 Persen Triwulan II 2018. Penulis: Chitra Paramaesti Diakses pada tanggal 5 Desember 2018 dari https://bisnis.tempo.co/read/1127039/industri-makanan-dan-minumantumbuh-867-persen-triwulan-ii-2018 